\title{
Experimental study on dynamic splitting of recycled concrete using SHPB
}

\author{
Yubin $\mathrm{Lu}^{1, \mathrm{a}}$, Shuisheng $\mathrm{Yu}^{2}$, and Yong $\mathrm{Cai}^{1}$ \\ ${ }^{1}$ Ministry of Education Key Laboratory of Technology for Manufacturing Process, Southwest University of Science and \\ Technology, 621010 Mianyang, Sichuan, China \\ ${ }^{2}$ College of Resources and Civil Engineering, Northeastern University, Shenyang 110819, PR China
}

\begin{abstract}
To study the recycled concrete splitting tensile properties and fracture state with various recycled coarse aggregate replacement percentage (i.e. $0 \%, 25 \%, 50 \%, 75 \%$ and 100\%), the dynamic splitting test of recycled concrete was carried out using large diameter $(75 \mathrm{~mm}$ ) split Hopkinson pressure bar (SHPB). The results show that the recycled concrete splitting tensile strength increases with the increase of loading rate, and the loading rate also affects the recycled concrete fracture state, which indicates that the recycled concrete has obvious rate sensitivity. The damage state of the recycled concrete is not only the destruction of the interface between coarse aggregate and cement mortar, but also associates with the fracture damage of aggregates. Under the same water cement ratio, when the replacement percentage of coarse aggregates is around $50 \%-75 \%$, the gradation of natural and recycled coarse aggregate is optimal, and thus the splitting tensile strength is the largest. This study offers theoretical basis for the engineering applications of recycled concrete.
\end{abstract}

\section{Introduction}

Recycled concrete is a new type of concrete that made from the disuse concrete after a series of courses of disposal, such as breaking up, washing, filtration, classification, combination on a certain proportion and so on [1]. Recycled concrete can realize the effective recycling of waste concrete, for protecting environment, saving resources, developing ecological architecture are of great significance, which is often considered as one of the main measures of developing green ecological concrete [2]. So far, in the tensile test of concrete studies, scholars [314] studied the tensile properties of concrete under quasi static or dynamic loading from different perspectives, and many different results were obtained. The results related with the concrete strength grade, water cement ratio, aggregate type, particle size distribution, testing methods and so on. But the research of dynamic splitting tensile properties of recycled concrete is less. Based on this, the dynamic splitting tensile test was carried out using $75 \mathrm{~mm}$ diameter split Hopkinson pressure bar (SHPB) in this study, researching the recycled concrete dynamic splitting mechanics performance and fracturing situation, discussing the influence of recycled coarse aggregate replacement percentage to recycled concrete splitting strength, accumulating the data of dynamic splitting tensile properties of recycled concrete, and providing reference for the engineering application of recycled concrete.

${ }^{\mathrm{a}}$ Corresponding author: yubinluzju@hotmail.com

\section{SHPB test principles, test materials and combination ratio}

\subsection{Test principles}

The dynamic splitting tests were carried out using the $75 \mathrm{~mm}$ diameter split Hopkinson pressure bar with the Brazilian disc tensile test method, which is also known as the splitting test and is widely used in tensile strength tests. The splitting test is adopted as the standard method for determination of the tensile strength of concrete by many international concrete specifications [e.g. 14-17]. The test schematic is shown in Fig. 1.

Based on the analysis of dynamic splitting tensile experimental data, $\mathrm{Li}$ et al. [18] pointed out that the calculation formula with modifying the nonuniform effect should be adopted. The time starting point is when the left end of specimen is loaded, the transmitted waveform is translated to the left with the time of $t_{0}$ and $\varepsilon_{t}^{*}(t)$ is obtained, namely $\varepsilon_{t}^{*}(t)=\varepsilon_{t}\left(t+t_{0}\right)$, which can eliminate the influence of the time nonuniformity on the test results. At the same time, due to using the three measured waves to calculate, the influence of the spatial inhomogeneity can also be eliminated. So the loading force on the specimen ends in the splitting test is,

$$
P(t)=\frac{\pi E R^{2}}{2}\left(\varepsilon_{i}(t)+\varepsilon_{r}(t)+\varepsilon_{t}^{*}(t)\right)
$$

where $E$ is the elastic modulus of SHPB bars, $R$ is the radius of SHPB bars, $\varepsilon_{i}(t)$ and $\varepsilon_{r}(t)$ is the incident wave and reflected wave, respectively. So the maximum value of $P(t), P_{\max }$, can be got, and then the dynamic splitting

This is an Open Access article distributed under the terms of the Creative Commons Attribution License 4.0, which permits unrestricted use, distribution, and reproduction in any medium, provided the original work is properly cited. 


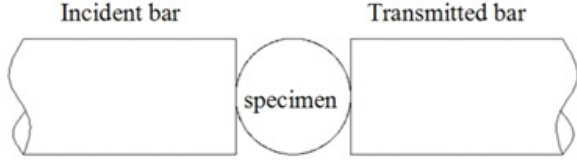

Figure 1. Sketch of dynamic splitting test.

Table 1. The combination ratio of recycled concrete in test.

\begin{tabular}{|l|l|l|l|l|l|}
\hline $\begin{array}{l}\text { Specimen } \\
\text { type }\end{array}$ & PC-0 & RC-25 & RC-50 & RC-75 & RC-100 \\
\hline Cement & 1 & 1 & 1 & 1 & 1 \\
\hline Water & 0.477 & 0.477 & 0.477 & 0.477 & 0.477 \\
\hline Sand & 1.465 & 1.465 & 1.465 & 1.465 & 1.465 \\
\hline $\begin{array}{l}\text { Natural } \\
\text { coarse } \\
\text { aggregate }\end{array}$ & 3.418 & 2.564 & 1.709 & 0.854 & 0 \\
\hline $\begin{array}{l}\text { Recycled } \\
\text { coarse } \\
\text { aggregate }\end{array}$ & 0 & 0.854 & 1.709 & 2.564 & 3.418 \\
\hline $\begin{array}{l}\text { Replacement } \\
\text { percent- } \\
\text { age/\% }\end{array}$ & 0 & 25 & 50 & 75 & 100 \\
\hline
\end{tabular}

tensile strength, $f_{t d}$, can be calculated,

$$
f_{t d}=\frac{2 P_{\max }}{\pi L D}
$$

in which $L$ and $D$ is the thickness and diameter of specimens, respectively.

Additionally, the loading rate in the specimen can be estimated by $f_{t d} / \tau$, where $\tau$ is the time lag between the start of the transmitted stress wave and the maximum transmitted stress wave.

\subsection{Test materials and combination ratio}

Raw materials used for recycled concrete specimens are (1)recycled coarse aggregates taken from waste concrete of a Mianyang road, the design strength of this waste concrete is unclear, and the waste concrete is broken by a jaw crusher, graded and cleaned to recycled coarse aggregates of diameters from 10 to $20 \mathrm{~mm}$; (2)natural coarse aggregates are natural cobbles of diameters from 10 to $20 \mathrm{~mm}$; (3)ordinary Portland cement of 42.5 grade is used; (4)fine aggregates are natural river sand of continuous grading with fineness modulus of 2.28; and (5)Mianyang tap water is used.

Concrete mix proportions largely influence the mechanical properties of concrete. To ensure the flowability during concreting and the strength after molding of recycled concrete, the mix proportions of recycled concrete specimens used in this study are cement: water: fine aggregate: coarse aggregate $=1: 0.477: 1.467: 3.422$, where coarse aggregates include natural coarse aggregates and recycled coarse aggregates. According to the difference of replacement ratios of recycled coarse aggregates, there are five different types of specimens, as shown in Table 1. PC-0 stands normal concrete specimens, and RC-25, RC-50, RC-75 and RC-100 stand recycled concrete specimens with recycled coarse aggregate replacement ratio of $25 \%, 50 \%, 75 \%$ and $100 \%$,
Table 2. The results of quasi-static splitting tests.

\begin{tabular}{|c|c|c|c|}
\hline $\begin{array}{l}\text { Replacement } \\
\text { percentage }\end{array}$ & Number & $\begin{array}{l}\text { Splitting } \\
\text { strength } \\
/ \mathrm{MPa}\end{array}$ & $\begin{array}{l}\text { Average } \\
\text { of splitting } \\
\text { strength /MPa }\end{array}$ \\
\hline \multirow{3}{*}{0} & A-1 & 3.27 & \multirow{3}{*}{3.07} \\
\hline & A-2 & 3.04 & \\
\hline & A-3 & 2.89 & \\
\hline \multirow{3}{*}{$25 \%$} & B-1 & 2.81 & \multirow{3}{*}{2.68} \\
\hline & B-2 & 2.48 & \\
\hline & B-3 & 2.74 & \\
\hline \multirow{3}{*}{$50 \%$} & C-1 & 3.34 & \multirow{3}{*}{3.24} \\
\hline & $\mathrm{C}-2$ & 3.38 & \\
\hline & $\mathrm{C}-3$ & 3.00 & \\
\hline \multirow{3}{*}{$75 \%$} & D-1 & 3.17 & \multirow{3}{*}{3.06} \\
\hline & D-2 & 2.98 & \\
\hline & D-3 & 3.05 & \\
\hline \multirow{3}{*}{$100 \%$} & E-1 & 2.39 & \multirow{3}{*}{2.31} \\
\hline & E-2 & 2.12 & \\
\hline & E-3 & 2.41 & \\
\hline
\end{tabular}

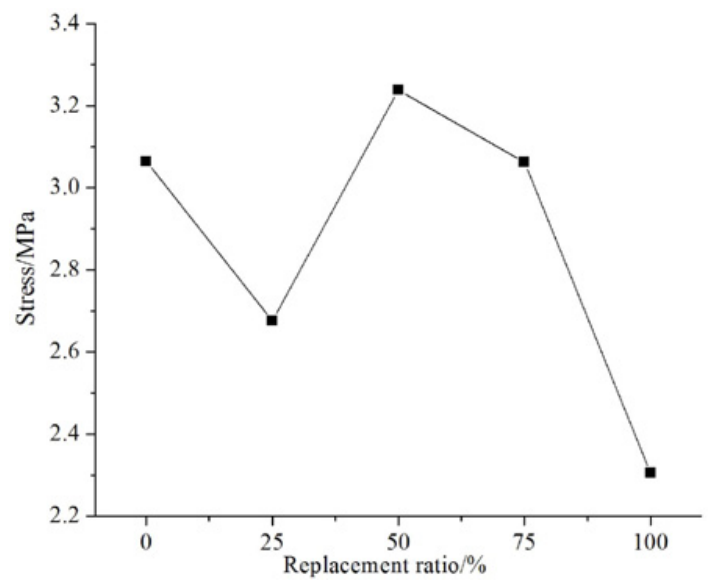

Figure 2. Relation of average quasi-static splitting strength of recycled concrete and replacement ratio of coarse aggregates.

respectively. The diameter and thickness of cylindrical specimens is 74 and $37 \mathrm{~mm}$, respectively. Specimens with the same dimensions are used in the quasi-static splitting tests.

\section{The test results and discussion}

In the dynamic splitting tests, to ensure that uniform stress state can be achieved as early as possible in the reclycled concrete samples, the amplitude of pulse oscillation can be reduced, and correct pulse shape is obtained for approximate constant strain-rate loading, soft rubber (bicycle inner tube) with the diameter of $20 \mathrm{~mm}$ and the thickness of $1.5 \mathrm{~mm}$ is employed as pulse shapers through multiple trial tests.

\subsection{The test results}

The quasi-static splitting tests were carried out with the MTS-815 Flex Test GT rock mechanics test system, and the test results are summarized in Table 2.

The quasi-static splitting test results are shown in Fig. 2. From Fig. 2, it is observed that, in the quasi-static 


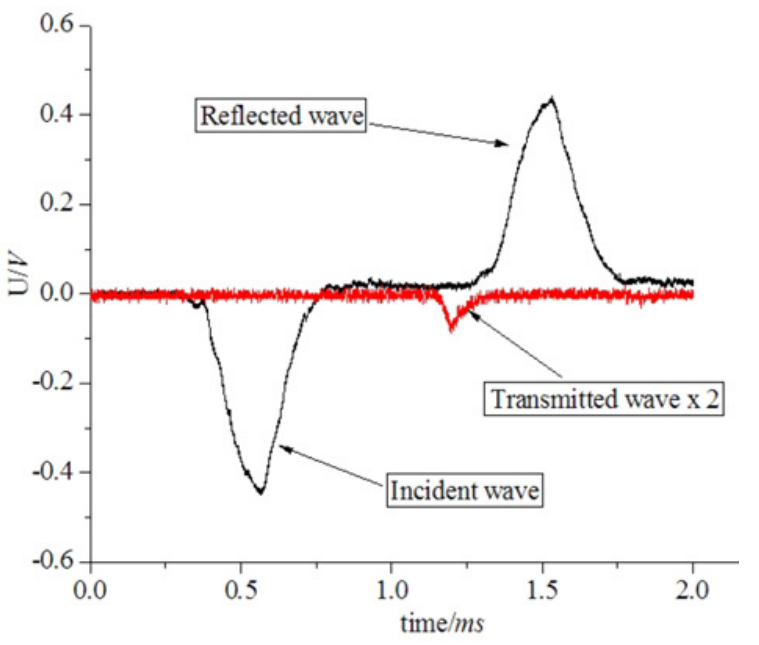

Figure 3. Typical waveforms of dynamic splitting tests.

splitting tests, the relationship between the splitting tensile strength and the recycled coarse aggregate replacement ratio has no obvious regularity. When the replacement percentage is $75 \%$, the splitting tensile strength of recycled concrete approaches that of normal concrete, while the replacement percentage is $25 \%$ and $100 \%$, the splitting tensile strength of recycled concrete is obviously lower than that of normal concrete with $12.7 \%$ and $24.8 \%$, respectively, and when the replacement percentage is $50 \%$, the tensile splitting strength is $5.7 \%$ higher than that of normal concrete. These results does not agree with those of Yang et al. [19], who thought that the recycled concrete tensile strength is decreased with the increase of recycled coarse aggregate replacement percentage. However, these results are consistent with the quasi static compressive test results of Xiao et al. [20], who found that when the recycled coarse aggregate replacement percentage was $50 \%$, the compressive strength of recycled concrete was higher than that of normal concrete. They suggested that the reason may be the gradation of recycled coarse aggregate and natural aggregate being best under this situation, or may be due to the randomicity of the test results.

The typical waveform of recycled concrete specimens in SHPB tests is shown in Fig. 3. It is seen from Fig. 3 that the transmission wave is far less than the incident wave, which is because that the contact face between specimen and SHPB bars is tangent, the contact area is small, the density and wave velocity of the recycled concrete specimen are smaller than those of the SHPB bar material, making its wave impedance less compared with that of SHPB bars, and leading to the signal on the transmission bar being smaller [21]. The dynamic splitting tensile strength was obtained at different impact air pressures (i.e. $0.4,0.5$ and $0.6 \mathrm{MPa}$ ) according to the transmission wave signals of recycled concrete specimens, and the experimental data are summarized in Table 3.

To describe the enhancement of dynamic splitting tensile strength of recycled concrete specimens, the dynamic splitting tensile strength increase factor is defined as,

$$
D I F=f_{t d} / f_{t s}
$$

Table 3. The results of dynamic splitting tests.

\begin{tabular}{|c|c|c|c|c|}
\hline $\begin{array}{l}\text { Replacement } \\
\text { percentage }\end{array}$ & $\begin{array}{l}\text { Air pressure/ } \\
\mathrm{MPa}\end{array}$ & Number & $\begin{array}{l}\text { Splitting } \\
\text { strength } \\
/ \mathrm{MPa}\end{array}$ & $\begin{array}{l}\text { Average } \\
\text { of } \\
\text { splitting } \\
\text { strength } \\
\text { /MPa }\end{array}$ \\
\hline \multirow{6}{*}{$0 \%$} & \multirow{2}{*}{0.4} & A-1 & 3.10 & \multirow{2}{*}{3.19} \\
\hline & & A-2 & 3.28 & \\
\hline & \multirow{2}{*}{0.5} & A-5 & 5.90 & \multirow{2}{*}{7.56} \\
\hline & & A-6 & 9.22 & \\
\hline & \multirow{2}{*}{0.6} & A-8 & 9.50 & \multirow{2}{*}{10.26} \\
\hline & & A-9 & 11.02 & \\
\hline \multirow{7}{*}{$25 \%$} & \multirow{2}{*}{0.4} & B-1 & 3.15 & \multirow{2}{*}{3.03} \\
\hline & & B-2 & 2.91 & \\
\hline & \multirow{3}{*}{0.5} & B-4 & 7.76 & \multirow{3}{*}{7.47} \\
\hline & & B-5 & 5.23 & \\
\hline & & B-6 & 9.41 & \\
\hline & \multirow{2}{*}{0.6} & B-7 & 11.60 & \multirow{2}{*}{11.47} \\
\hline & & B-8 & 11.33 & \\
\hline \multirow{8}{*}{$50 \%$} & \multirow{2}{*}{0.4} & $\mathrm{C}-1$ & 3.17 & \multirow{2}{*}{3.61} \\
\hline & & $\mathrm{C}-2$ & 4.04 & \\
\hline & \multirow{3}{*}{0.5} & $\mathrm{C}-4$ & 8.30 & \multirow{3}{*}{9.09} \\
\hline & & $\mathrm{C}-5$ & 8.00 & \\
\hline & & C-6 & 10.98 & \\
\hline & \multirow{3}{*}{0.6} & C-7 & 14.72 & \multirow{3}{*}{14.17} \\
\hline & & C-8 & 12.96 & \\
\hline & & C-9 & 14.82 & \\
\hline \multirow{8}{*}{$75 \%$} & \multirow{3}{*}{0.4} & D-1 & 4.79 & \multirow{3}{*}{4.70} \\
\hline & & D-2 & 3.98 & \\
\hline & & D-3 & 5.32 & \\
\hline & \multirow{3}{*}{0.5} & D-4 & 9.68 & \multirow{3}{*}{9.13} \\
\hline & & D-5 & 9.66 & \\
\hline & & D-6 & 8.05 & \\
\hline & \multirow{2}{*}{0.6} & D-7 & 11.15 & \multirow{2}{*}{10.28} \\
\hline & & D-9 & 9.40 & \\
\hline & 04 & E-1 & 2.99 & 346 \\
\hline & 0.4 & E-2 & 3.93 & 3.46 \\
\hline & & E-4 & 6.91 & \\
\hline & 0.5 & E-5 & 10.40 & 7.69 \\
\hline $100 \%$ & & E-6 & 5.75 & \\
\hline & & E-7 & 10.80 & \\
\hline & 0.6 & E-8 & 9.13 & 10.45 \\
\hline & & E-9 & 11.41 & \\
\hline
\end{tabular}

where $f_{t s}$ is the quasi-static splitting tensile strength of recycled concrete.

The relationship of the recycled concrete dynamic splitting tensile strength increase factor (DIF) and impact air pressure or loading rate is shown in Fig. 4. It is found that the DIF increases with the increase of impact air pressure or loading rate, which indicates that the dynamic splitting tensile strength of recycled concrete has obvious rate sensitivity, viz. the DIF largely increases with the increase of loading rate. Lu et al. [22] explained this kind of phenomenon, who believed that, in the macroscale level, the dynamic tensile strength enhancement obtained from dynamic tensile tests on concrete-like materials is a kind of material intrinsic property rather than caused by the structure effect. A micromechanics model was proposed by Lu et al. [22] based on the dynamic fracture mechanics from the analysis results, and the phenomenon was pointed 
(a)

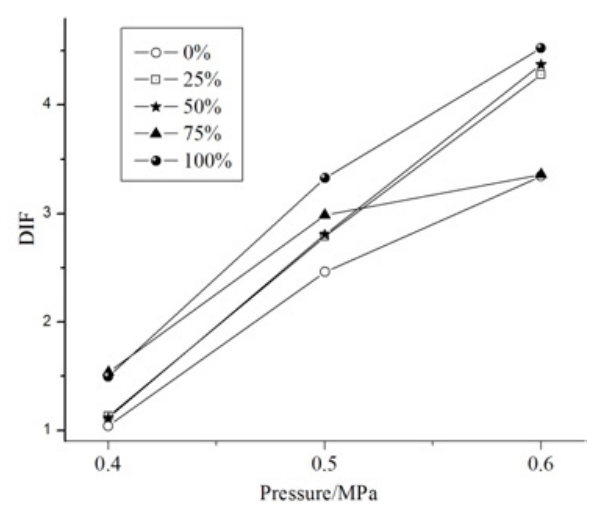

(b)

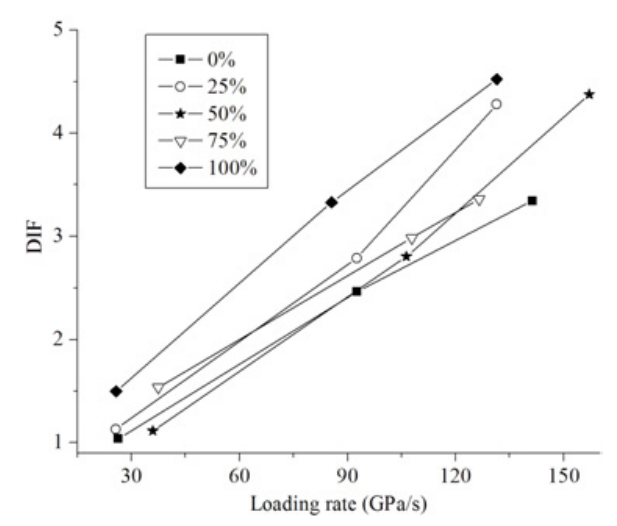

Figure 4. Relation of DIF with (a) impact gas pressure and (b) loading rate.

out to be largely caused by the inertia of micro cracks. Among the five groups of tests, when the replacement percentage is $0 \%$, the DIF is lower than that under other replacement percentages, which reveals that strain-rate sensitivity of the dynamic splitting tensile strength of normal concrete is relatively low.

As shown in Fig. 5, the dynamic splitting failure pattern of recycled concrete specimens is mainly breaking into two parts symmetrically along the loading axis, meeting the test validity condition of conventional Brazilian disc tests [23]. When the impact air pressure is small, namely the impact velocity is small, and the dynamic splitting fracture form of recycled concrete specimens is appearing crushed zones along the radial loading end surfaces and splitting into two parts with large blocks. With the increase of loading velocity, the pressure along the radial direction increases, the crushing area also increases, the critical crack initial length of specimen decreases and the range of crack angles that can be extended increases. Thus, the number of extending cracks increases, the size of fragments decreases, the broken degree of specimen increases, and the specimen local failure gradually becomes obvious. This reflects the rate sensitivity of recycled concrete on its splitting tensile failure mode, which indicates the strain-rate effect of recycled concrete from another view. (a) $0.4 \mathrm{MPa}$

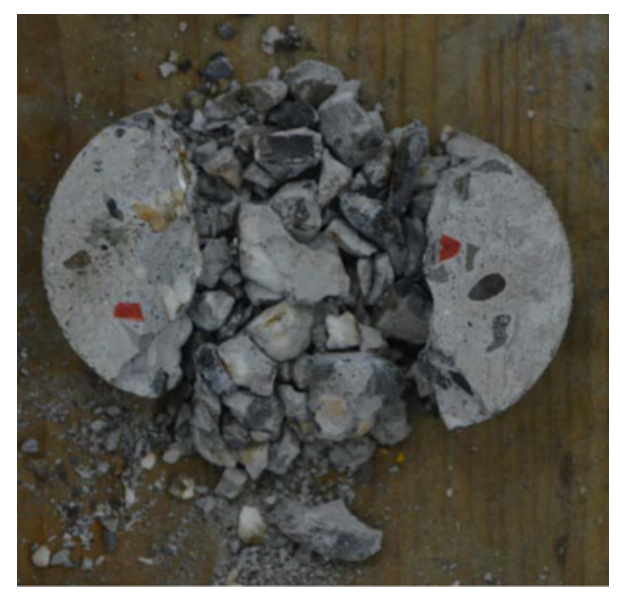

(b) $0.5 \mathrm{MPa}$

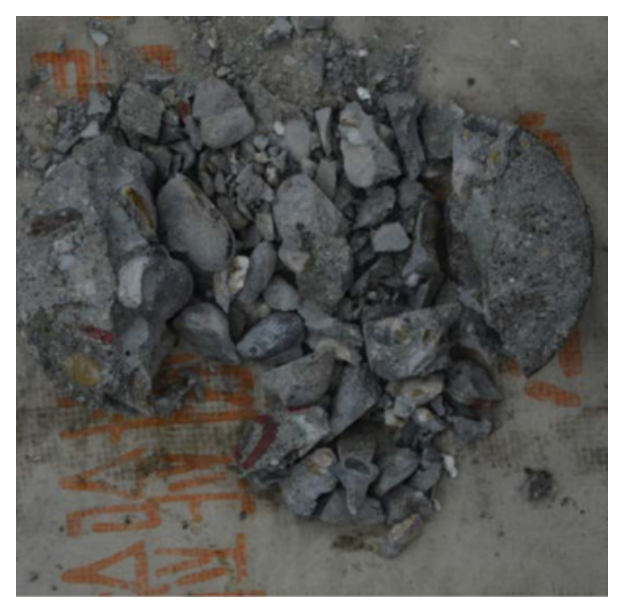

(c) $0.6 \mathrm{MPa}$

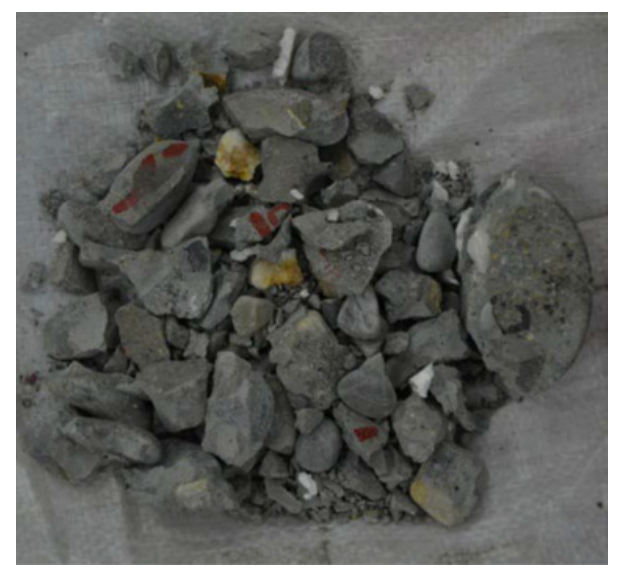

Figure 5. The destruction state of recycled concrete under different impact air pressures.

\subsection{The relationship between recycled concrete dynamic splitting tensile strength and recycled coarse aggregate replacement percentage}

The relationship between the average dynamic splitting tensile strength of recycled concrete under different impact air pressures and recycled coarse aggregate replacement percentage is shown in Fig. 6. 


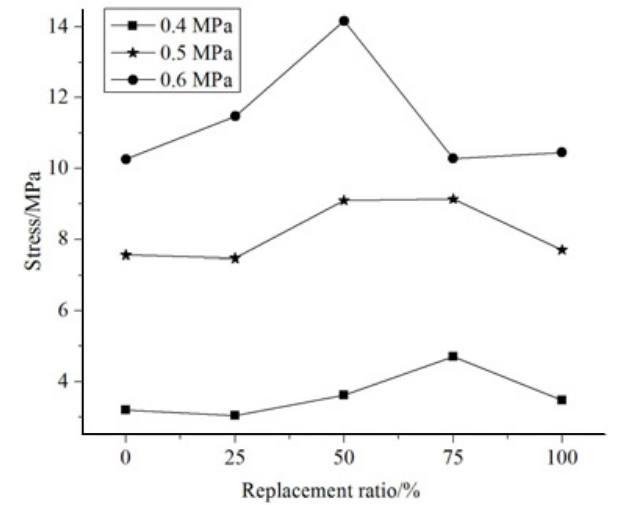

Figure 6. Relation between the average dynamic splitting tensile strength of recycled concrete and replacement ratio of coarse aggregates under different gas pressures.

It shows that the dynamic splitting tensile strength under different recycled coarse aggregate replacement percentages is basically greater than that of normal concrete. Under the impact air pressure of $0.4 \mathrm{MPa}$, the average dynamic splitting tensile strength of recycled concrete increases with the range from $-5 \%$ to $47.3 \%$ compared with that of normal concrete; when the replacement percentage is $75 \%$, the increase is maximum with $47.3 \%$; and it is $25 \%$, the average dynamic splitting tensile strength decreases by $5 \%$. Under the impact air pressure of $0.5 \mathrm{MPa}$, when the replacement percentage is $75 \%$, the increase is largest with $20.8 \%$; the strength of RAC with the replacement percentage of $50 \%$ is basically equal with that of $75 \%$; and it is $25 \%$, the strength decreases by $1.2 \%$. Under the impact air pressure of $0.6 \mathrm{MPa}$, when the replacement percentage is $50 \%$, the increase is also largest with $38.1 \%$; and it is $75 \%$, the strength of RAC is basically equal with that of normal concrete. Accordingly, under $0.4,0.5$ and $0.6 \mathrm{MPa}$, when the recycled coarse aggregate replacement percentage are $50 \%$ and $75 \%$, the dynamic tensile splitting strength of recycled concrete is the largest, which is consistent with the quasi-static splitting test results. Therefore, experimental results in this study indicate that when the replacement percentage of recycled coarse aggregate is around $50 \%-75 \%$, its gradation is best with natural coarse aggregate.

From the increase value of recycled concrete dynamic tensile splitting strength under different air pressure, it can be seen that with the increase of recycled coarse aggregate replacement percentage, the dynamic splitting tensile strength appears the phenomenon of first increase and then decrease. The reasons for this phenomenon can be approximately explained by the following points. (1) In dynamic splitting tests, under the same recycled coarse aggregate replacement percentage, because of the micro crack inertia effect the aggregate crack extension requires higher loading to make aggregate fracture (as shown in Fig. 7), leading concrete specimen damage, thus the recycled concrete dynamic splitting tensile strength increases. (2) Due to the production of new micro cracks and fracture on the recycled coarse aggregate, the mechanical properties of recycled coarse aggregates
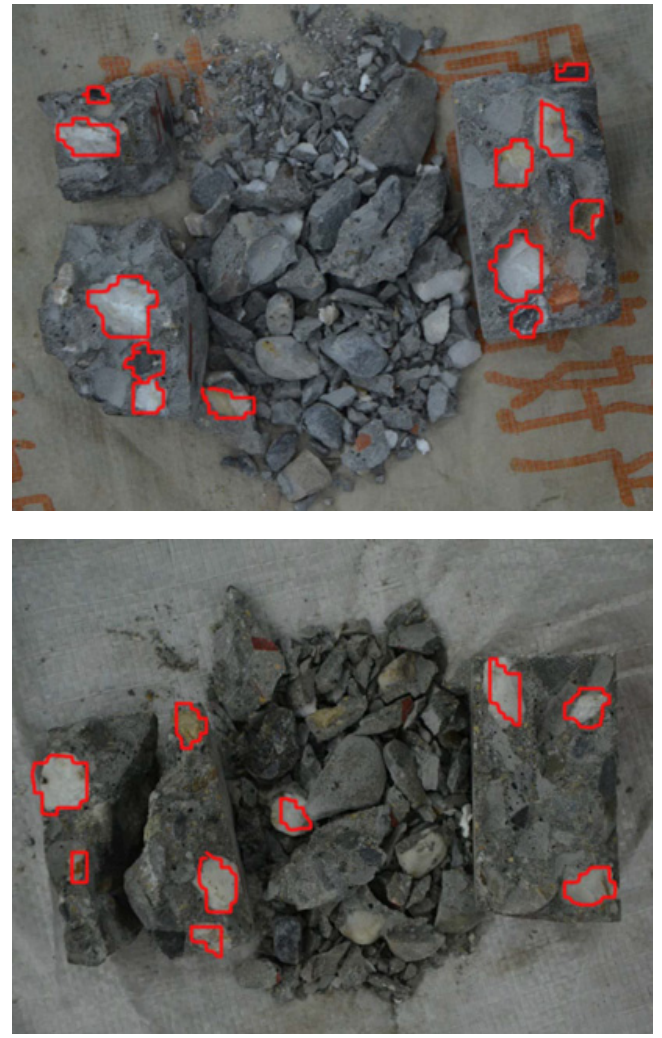

Figure 7. Fracture state of coarse aggregates.

are lowered. On the other hand, because recycled coarse aggregates are wrapped by cement mortar, the hydrophilic of recycled coarse aggregates is relatively strong, and many micro cracks on the recycled coarse aggregate surfaces take in new cement particles, making the hydration of contact areas between the recycled coarse aggregate and cement mortar more completely, forming dense interface structures, and thus improving the chemical bonding strength of interfaces. In a word, the mechanical properties of recycled concrete are influenced by recycled coarse aggregate and the chemical bonding strength of interfaces. (3) When the recycled coarse aggregate replacement percentage is around 50\%-75\%, the gradation between the recycled and natural coarse aggregates is best, so the dynamic splitting tensile strength is relatively lager. With the increase of replacement percentage, the influence of recycled coarse aggregates is greater than the chemical bonding strength of interfaces. Since the mechanical properties of recycled coarse aggregates is reduced, the dynamic splitting tensile strength of recycled concrete decreases.

\section{Conclusions}

In this study, the dynamic splitting test of recycled concrete (recycled coarse aggregate replacement percentage is $0 \%, 25 \%, 50 \%, 25 \%$ and $100 \%$ ) was carried out using large diameter $(75 \mathrm{~mm})$ SHPB, meanwhile the quasi-static splitting test was carried out, the following conclusions are drawn.

(1) In dynamic splitting tests, when the recycled coarse aggregate replacement percentage is around $50 \%-75 \%$, the 
dynamic splitting tensile strength of recycled concrete is largest, this is consistent with the results in quasi-static splitting tests, which further validates that at this situation the gradation formed between recycled and natural coarse aggregates is best.

(2) Because of the micro crack inertia effect, the aggregate crack extension requires higher loading to make aggregate fracture, leading concrete specimen damage, thus the dynamic splitting tensile strength of recycled concrete increases. The strain-rate sensitivity of recycled concrete is obvious, and the fragment degree of recycled concrete is influenced by the strain-rate.

(3) Due to the appearance of new micro cracks and fracture on the recycled coarse aggregate, the recycled coarse aggregate mechanical properties decrease. As recycled coarse aggregates are wrapped by cement mortar, the hydrophilic is relatively strong, and many micro cracks on the recycled coarse aggregate surfaces intake new cement particles, making the hydration of contact areas between recycled coarse aggregates and cement mortar more prefect, forming dense interface structures, and thus improving the chemical bonding strength of interfaces. In a word, the mechanical properties of recycled concrete are influenced by both coarse aggregates and the chemical bonding strength of interfaces.

The authors would like to acknowledge the sponsor by the National Natural Science Foundation of China (51308480).

\section{References}

[1] J. Z. Xiao, J. B. Li, Y. Lan. Concrete, 25, 17-20 (2003) (in Chinese)

[2] Z. X. Xing, Y. N. Zhou. J. North China Institute Water Conservancy Hydroelectric Power, 19:30-32 (1998) (in Chinese)

[3] J. W. Tedsco, C. A. Ross, S. T. Kuennen. ACI Mater. J., 90, 162-169 (1993)

[4] B. L. Atchley, H. L. Furr. ACI Mater. J., 64, 745-756 (1967)

[5] M. L. Hughes, J. W. Tedesco, C. A. Ross. Comput. Struct., 47, 653-671 (1993)
[6] D. E. Lambert, C. A. Ross. Int J Impact Eng., 21(24): 985-998 (2000)

[7] J. T. Gomez, A. Shukla, A. Sharma. Theo. Appl. Fract. Mech., 25, 37-49 (2001)

[8] C. J. Jiao, G. P. Jiang, L. Gao. Acta Armament., 31, 469-472 (2010) (in Chinese)

[9] J. Hu, X. T. Wu. Explosive Shock Waves, 31, 402-406 (2011) (in Chinese)

[10] W. Sun, C. J. Jiao. J. Guangzhou Uni., 10, 42-47 (2011) (in Chinese)

[11] A. Behnood, M. Ghandehari. Fire Safe. J., 44, 1015-1022 (2009)

[12] Y. Choi, R. L. Yuan. Cem. Concr. Res., 35, 1587-1591 (2005)

[13] C. Parra, M. Valcuende, F. Gomez. Construct. Build. Mater., 25, 201-207 (2011)

[14] H. Tanyildizi, A. Coskun. Construct. Build. Mater., 22, 2269-2275 (2008)

[15] American Society for Testing and Materials (ASTM). Standard test method for spitting tensile strength of cylindrical of foam concrete. ASTM C496-90, 4:266269 (1991)

[16] British Standards Institution. BS1881:Part117: Testing concrete method for the determination of tensile strength. London: British Standards Institution (1983)

[17] ISO4108 (E) Concrete: Determination of tensile splitting strength of test specimens. International Standard, 1-3 (1980)

[18] W. Li, H. P. Xie, Q. Z. Wang. Explosive Shock Waves, 26, 12-20 (2006) (in Chinese)

[19] F. Yang, A. J. Chen, J. Wang, X. P. Sun. Concrete, 12, 11-14 (2012) (in Chinese)

[20] J. Z. Xiao, J. B. Li, Z. P. Sun, X. M. Hao. J. Tongji. Uni., 32, 1558-1561 (2004) (in Chinese)

[21] Q. Ping, Q. Y. Ma, J. S. Zhang, P Yuan, B. S. Chen. Chin J Rock Mech. Eng., 31, 3363-3369 (2012) (in Chinese)

[22] Y. B. Lu, H. J. Wu, L. M. Zhao. Explosive Shock Waves, 33, 275-281 (2013) (in Chinese)

[23] F. Q. Gong,X. B. Li, J. Zhao. Chin J Rock Mech. Eng., 29, 881-891 (2010) (in Chinese) 